\title{
A ENFERMAGEM NO PROCESSO DE GESTÃO ECONÔMICA DOS SERVIÇOS DE SAÚDE: LIMITES E POSSIBILIDADES ${ }^{1}$
}

\author{
NURSING IN THE PROCESS OF ECONOMIC MANAGEMENT OF HEALTH \\ SERVICES: LIMITATIONS AND POSSIBILITIES \\ LA ENFERMERIA EN EL PROCESO DE GESTIÓN ECONÓMICA DE LOS \\ SERVICIOS DE SALUD: LIMITES Y POSIBILIDADES
}

\author{
Maria Luiza Anselmi \\ Janete Rodrigues S. Nakao ${ }^{2}$
}

\begin{abstract}
RESUMO: Este artigo apresenta algumas reflexões acerca das possibilidades e limites da racionalização e flexibilização do processo de gestăo nos serviços de saúde sob a perspectiva econômica, focalizando a introdução de mecanismos e instrumentos centrados na responsabilizaçăo econômica e organizacional dos recursos e a participaçăo da enfermagem nestes processos. Discutese a adoção de um sistema de controle econômico que coordene os interesses dos diversos sujeitos envolvidos; privilegie os resultados dos processos e melhore a combinação econômica dos recursos. Sob essa perspectiva, dois conceitos säo considerados relevantes na elaboraçăo do orçamento do Serviço de Enfermagem: a controlabilidade dos recursos e a negociação nos processos de alocaçăo e utilização destes. A operacionalizaçăo desses conceitos no âmbito da (re)organizaçăo dos serviços de saúde, mais especificamente, na área de enfermagem cria novas possibilidades de participaçăo nos processos de produçăo de serviços, assegurando maior transparência nos processos decisórios e reconfigurando novas modalidades de gestăo para os serviços de enfermagem.
\end{abstract}

PALAVRAS-CHAVE: processo de gestão econômica, controle econômico, orçamento do Serviço de Enfermagem

\section{INTRODUÇÃO}

Os processos de redefinição de politicas sociais e econômicas e politicas, tanto nos paises considerados economicamente estáveis(desenvolvidos) como naqueles em fase de desenvolvimento, têm colocado a atençăo à saúde como uma questăo relevante e, nesse sentido, o setor saúde vem sendo tomado como objeto de análise e de intervenção.

A politica social implementada no pós-guerra(Estado de Bem Estar - Welfare State) nos países desenvolvidos, caracterizada por um modelo de proteçăo social orientado a assegurar certos direitos sociais fundamentais à existência humana, vem sofrendo severas contestações e tem sido considerada como principal razăo da crise no setor saúde. As dificuldades apontadas referem-se basicamente à incapacidade do Estado em sustentar o aumento crescente e incontrolável dos gastos em saúde (Anessi, 1993, Medici, 1994) e, consequentemente, dos

' Este trabalho constitui-se parte do estudo desenvolvido no Programa de Pós-Doutorado realizado na Scuola di Direzione Aziendale, Università Luigi Bocconi em Milão - Itália.

2 Professoras Doutoras do Departamento de Enfermagem Geral e Especializada da Escola de Enfermagem de Ribeirão Preto - Universidade de São Paulo 
custos relativos ao funcionamento dos serviços o que tem contribuído para elevaçăo do deficit público e um agravamento da crise fiscal do Estado. A alocaçăo irracional dos recursos para o setor, bem como a forte concentraçăo de gastos com procedimentos de alto custo, tem comportado uma ausência de correspondência entre o incremento dos gastos em saúde e seu respectivo impacto nos padrőes sanitários das populaçőes (Mendes, 1996) evidenciando desse modo, a ineficácia dos sistemas de saúde.

Nos anos 90, as propostas de reforma do setor saúde implementadas em diversos paises europeus(Inglaterra, Suécia, Itália entre outros) têm privilegiado a adoçăo de medidas racionalizadoras centradas na melhoria da eficiência através da contençăo/diminuiçăo de custos sem que isto provoque reflexos negativos nos niveis de saúde da populaçăo, ou seja, as estratégias utilizadas procuram equilibrar os objetivos da equidade, da eficiência e da qualidade. Nesse sentido, o maior desafio enfrentado no processo de (re)organizaçăo dos serviços de saúde tem sido o de consolidar os princípios de universalidade do sistema, considerando a saúde enquanto um direito universal dos cidadãos e, ao mesmo tempo, o de assegurar uma distribuiçăo e utilizaçăo dos recursos - financeiros, humanos e materiais que contemple a eficácia, eficiência e a economicidade do sistema visando a satisfação de necessidades individuais e coletivas de saúde da populaçăo.

Pactuamos com Mendes (1996) quando coloca que a crise na saúde é determinada estruturalmente e resulta da impossibilidade de conciliar o conflito entre as forças expansivas do sistema de saúde com seus mecanismos de controle. Propostas de reformas do setor baseadas apenas em estratégias/medidas de racionalizaçăo do sistema merecem ser analisadas com atençăo e cuidado a fim de que a politica sanitária não se reduza a uma mera questão econômica e o controle de custos converta-se em meta principal da planificaçăo e do esforço politico na saúde. Soluçőes efetivas à crise implicam portanto, que as medidas racionalizadoras(que privilegiam a melhoria da eficiência, eficácia e da economicidade do sistema) a serem introduzidas estejam vinculadas/subordinadas à superaçăo dos determinantes estruturais.

Embora concordando com Mendes (1996), entendemos que a superaçăo desses determinantes exigem um longo e árduo processo de debate e de lutas essencialmente políticas porém, neste momento, os serviços de saúde em seus processos de produçăo, vem requerendo respostas à problemática cada vez mais aguda no que diz respeito ao aumento da demanda, o qual tem gerado uma elevaçăo do consumo de serviços sem um correspondente aumento de recursos alocados, sejam eles financeiros, materiais ou humanos .

As necessidades de saúde săo ilimitadas enquanto os recursos econômicos disponiveis para atendê-las são escassos. Frente a esta escassez tem-se buscado algumas soluçōes racionalizadoras relativas ao funcionamento das estruturas de saúde, ou seja, propostas que permitam combinar os diferentes recursos disponiveis de maneira a obter resultados que garantam à populaçăo atendida nestes serviços, respostas quanti-qualitativas satisfatórias ao seu problema de saúde.

Nos paises europeus, a introduçăo da abordagem econômica nos processos de produçăo e de gestăo realizados no interior das instituiçőes de saúde já dispőe de uma certa tradiçăo e consistência teórico-prática. No Brasil, este debate vem se acentuando e se fazendo presente face às dificuldades, principalmente financeira, que os serviços têm enfrentado para assegurar o desenvolvimento de suas atividades.

Este trabalho propōe-se a desenvolver algumas reflexర్es acerca das possibilidades e limites da racionalizaçăo e flexibilizaçăo do processo de gestăo nos serviços de saúde sob a perspectiva económica, focalizando a introduçăo de mecanismos e instrumentos centrados na responsabilizaçăo económica e organizacional dos recursos na participaçăo da enfermagem nesses processos. 


\section{A SAÚDE COMO BEM E FUNÇÃO PÚBLICA}

A premissa inicial que fundamenta este trabalho é que a saúde é um bem público, cabendo ao Estado assegurá-lo à populaçăo. Com essa afirmaçăo estamos considerando a saúde como uma necessidade primária, imprevisivel e mutável no tempo. Primária porque o estado de doença limita e condiciona a possibilidade de acesso e consumo de outros bens e serviços e, portanto, a satisfaçăo de outras necessidades; essencialmente imprevisivel, uma vez que o momento de adoecimento, para o indivíduo, é totalmente aleatório, bem como a gravidade do evento, ou seja, não é possivel antecipar mecanismos de enfrentamentos ao processo de adoecer; associado a essas características, importante ressaltar que um bem público pressupōe a năo exclusăo no consumo, o que significa que mesmo quem năo utiliza diretamente o serviço de saúde também será beneficiado(por exemplo: a vacinaçăo); outro aspecto fundamental a ser considerado é que o bem - saúde, envolve uma necessidade de conhecimento, ou seja, o indivíduo necessita de informaçóes para saber se a necessidade percebida existe realmente, o que caracteriza uma assimetria no nivel de informaçőes entre quem demanda as ações de saúde e quem as oferece. As informações acerca do processo de adoecer é de domínio da oferta(serviços de saúde/profissionais) e năo da demanda(clientes/ pacientes) Ȧ clientela dos serviços de saúde só é possivel obter essas informações através da intermediação de seus profissionais.

Uma segunda premissa refere-se às particularidades que caracterizam o processo de produçăo de serviços de saúde, as quais determinam também a maneira como se dará o processo de gestão econômica(e mecanismos operativos). Tais peculiaridades envolvem os seguintes aspectos: os resultados(produtos) obtidos săo intangiveis, ou seja, apresentam uma limitada perceptibilidade física, além de năo serem armazenáveis dada a conjunçăo espaçotemporal em que os processos de produçăo e de consumo do serviço acontecem;

- a năo transferência do bem/produto, que dadas as condições referidas anteriormente năo pode ser transportado e portanto, utilizado em lugares diversos daquele onde foi produzido;

- a quantidade de força de trabalho absorvida para realizaçăo da produção é superior à quantidade de capital empregado por unidade produzida;

- a forte interaçăo entre o sujeito que produz e o sujeito que usufrui da utilidade do bem/ produto;

- os profissionais que desenvolvem o trabalho/produçăo detém um grau elevado de autonomia clinica sendo capazes de definirem năo apenas a "real" necessidade da clientela mas também o modo como essas serăo satisfeitas;

- a ausência do elemento lucro como finalidade institucional e indicador sintético da economicidade da organizaçăo(considerando que o "bem" saúde tem um caráter público e portanto, não tem sua produçăo orientada pela lógica e mecanismos de mercado);

- os mecanismos de troca(entre quem produz e quem consome) são "atípicos", ou seja, năo săo definidos pelas regras de mercado, também denominada conveniência económica (Borgonovi, 1996). A cessăo dos serviços à clientela năo ocorre com base no preço(elemento que objetiva o valor de um bem exprimindo um juizo de utilidade e, constituindo-se portanto, num mecanismo de seleçăo da demanda). Nos serviços de saúde(públicos), embora a aquisiçăo dos fatores produtivos necessários para o desenvolvimento da produção(transformação fisicotécnica) seja realizada através de um processo de troca típica (com base no preço definido pelo mercado), no momento de cessăo e consumo do produto pela clientela essa troca é "atípica", ou seja, năo envolve um valor objetivo de troca(preço) (Borgonovi, 1990) 


\section{O PROCESSO DE CONTROLE ECONÓMICO NA PRODUÇÃO DE SERVIÇOS DE SAÚDE}

A sobrevivência econômica de uma organizaçăo(no caso os serviços de saúde) é determinada por uma série de condiçŏes, tais como: as politicas de saúde; as determinaçőes legais de funcionamento das estruturas; os niveis de financiamento destinados ao setor, a capacidade de "governar" o processo de transformaçăo dos elementos produtivos e das condiçőes de produção através da definiçăo de modalidades de combinaçăo econômica dos recursos colocados à disposiçăo. É nessa última esfera que o processo de controle econômico assume relevância à medida em que possibilita a instrumentalização da gerência na tomada de decisăo, na coordenaçăo e conduçăo da produçăo com vistas a alcançar as finalidades institucionais; favorece a atuação das diversas profissionalidades envolvidas no processo de produção de serviços, năo pela subordinação da autonomia profissional a determinados critérios econômicos, mas potencializando as açőes destes profissionais através de uma melhor utilizaçăo dos recursos com vistas a obter resultados coerentes às necessidades de saúde da coletividade. Estamos considerando que os serviços de saúde apresentam uma natureza pública e, nesse sentido, devem responder à tutela de interesses gerais e coletivos(que são conflitantes) e năo a interesses particulares. Portanto, não são coerentes com tal pressuposto, os critérios de discriminação de acesso ao consumo de serviços, os quais devem estar fundamentados nos valores e necessidades expressos pela coletividade e mediados pelos canais institucionais e de confronto social que se traduzem em políticas para o setor. Os únicos elementos que podem limitar esse consumo referem-se aos recursos disponiveis e ao nivel de eficiência com que estes săo utilizados. Assim, a busca do equilibrio econômico năo se constitui em critério principal à seleçăo da demanda, mas sim em um dos aspectos a ser respeitado (Borgonovi, 1990).

A complexidade que distingue as instituiçőes de saúde resultante, seja da crescente incorporaçăo tecnológica em seus processos de trabalho, seja pela forma peculiar como este trabalho ocorre e de suas articulaçōes com os demais setores da produçăo econômica, impōem progressivamente ao sistema de gestão a necessidade de redefinir mecanismos de alocação de recursos, de monitoraçăo da situaçăo institucional, de verificaçăo contínua e sistemática da congruência global dos objetivos sob o perfil econômico-financeiro.

O processo de controle econômico que estamos tratando envolve um conjunto de instrumentos de mensuraçăo, análise e interpretaçăo das atividades/programas desenvolvidos na organizaçăo, em termos de fluxo de valores econômicos, com a finalidade de gerar decisőes capazes de orientar as açōes com vistas aos objetivos econômicos. Ainda, busca identificar modalidades inovadoras para o desenvolvimento das atividades tomando com ponto de referência os processos realizados e os resultados obtidos.

A lógica subjacente nesse processo procura superar o conceito de controle burocrático ainda vigente nas instituiçőes de saúde e que na maioria das vezes está associado, somente e exclusivamente, à verificaçăo da execuçăo correta dos procedimentos, das operações e ao cumprimento das normas e rotinas. Nesse sentido, o termo controle tem assumido, no âmbito da administração de serviços de saúde, uma conotaçăo altamente depreciativa. O controle econômico que pretendemos discutir e refletir procura identificar modalidades inovadoras para o desenvolvimento das atividades tomando como ponto de referência os processos realizados e os resultados obtidos, ou seja, assume como objeto de análise e avaliaçăo a relaçăo recursosresultados e năo os procedimentos técnico-operativos ou formais da produçăo. Sob essa perspectiva, os profissionais de saúde dispõem de amplos espaços de autonomia e liberdade para participação na escolha das modalidades de açăo em funçăo dos objetivos estabelecidos, dos recursos disponiveis e dos resultados almejados, os quais devem ser discutidos e conhecidos em todos os niveis da instituiçăo a fim de garantir transparência seja das informações como das decisões.

Os instrumentos adotados no processo de controle econômico devem criar possibilidades 
de mensuraçăo dos resultados obtidos em termos de recursos utilizados e serviços prestados, além de consentirem a avaliação das variaçōes e respectivos motivos, ou seja, das razōes dos "afastamentos" verificados em termos dos objetivos definidos, permitindo estabelecer correlações entre responsabilidade econômica e responsabilidade organizacional nesses processos.

Dentre os vários instrumentos que permitem a concretização de um sistema de gestão econômica(onde se insere o controle econômico) emergem como relevantes:

- a contabilidade analítica estruturada por Centros de Responsabilidade(CdR) e respectivos centros de custos (Anthony; Young, 1992) cuja finalidade é a agregaçăo de informaçōes sobre o emprego dos fatores produtivos nos processos de produção e de consumo. Um Centro de Responsabilidade é entendido como um grupo de pessoas/atividades que atuam/são desenvolvidas com a finalidade de atingir determinados objetivos da organização sob a direção de uma pessoa responsável (Rappini; Zavattaro, 1994). Mediante tal estruturaçăo é possivel estabelecer o valor econômico que deriva da aquisição e da utilizaçăo(consumo) dos recursos alocados no processo de prestação de serviços;

- o orçamento, um plano que exprime em termos quantitativos e qualitativos os programas da organizaçăo, os recursos disponiveis e os resultados a alcançar num determinado periodo de tempo; representa uma modalidade de tomada de decisão mediante a introduçăo de dois principios: o da transparência e o da unidade espaço-temporal das decisões, de modo a permitir a verificaçăo da compatibilidade econômico-financeira e técnica ao nivel global da organizaçăo. Configura-se ainda num instrumento de coordenação e de integração, uma vez que preside a decomposição progressiva dos objetivos gerais da organizaçăo em objetivos especificos que devem ser coerentes com as responsabilidades atribuidas às várias unidades operativas da organização.

Ambos os instrumentos concretizam-se na prática gerencial de forma articulada e interdependente. A operacionalização tanto da contabilidade analitica como do orçamento requerem como primeiro passo a predisposição do Plano dos Centros de Responsabilidade onde as responsabilidades sobre a alocação dos recursos e as ações efetivamente desenvolvidas são explicitadas e articuladas às responsabilidades formais da organização

Cada CdR comporta a definição de conteúdos e espaços de autonomia e de responsabilização cuja representação encontra-se na Figura 1.

FIGURA 1. Âmbitos de autonomia e responsabilidade dos Centros de Responsabilidade

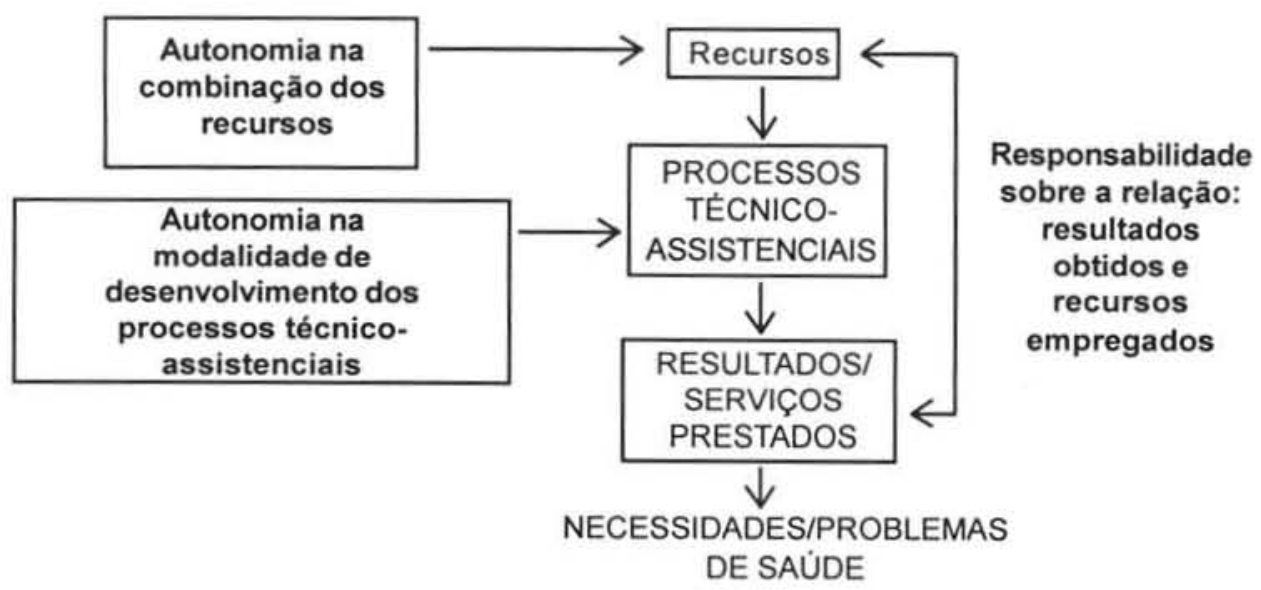

Fonte: Pessina; Bergamaschi; Zavattaro, 1996. 
Pela Figura 1, a correlaçăo entre recursos empregados e resultados especificos alcançados devem ser explicitados de modo a permitir propostas de ações inovadoras que potencializem mudanças e racionalização da gestăo, ao mesmo tempo em que assegurem a autonomia na combinação dos recursos e nas modalidades de desenvolvimento dos processos técnicoassistenciais.

O elemento de referência para a definiçăo dos $C$ dR é a estrutura organizacional onde são evidenciados: os critérios adotados para a divisão do trabalho; as diversas unidades que a compōem e as atividades desenvolvidas; e ainda, o esquema de inter-relaçőes existentes entre as unidades organizacionais.

Dada uma certa estrutura organizacional o plano de CdR sobrepőe-se a essa de forma articulada, ou seja, a cada unidade corresponde um CdR.

É ao nivel do CdR, unidade elementar produtiva da estrutura, que o orçamento assume centralidade no processo de controle econômico, uma vez que é neste âmbito que as ações consideradas prioritárias, os niveis de atividade e respectivos recursos necessários para alcançálos serăo definidos em função das diretrizes institucionais.

Nesse trabalho, não se pretende descrever o percurso técnico de elaboração do orçamento dentro de um $\mathrm{CdR}$ (o como) mas apontar dois conceitos considerados fundamentais que devem permear todo o processo. O primeiro, refere-se à controlabilidade que pressupőe a identificaçăo do grupo de atores da organização que efetivamente controlam determinadas variáveis, podendo ser responsabilizados sobre o desenvolvimento das atividades e, consequentemente, sobre os resultados alcançados. Embora nenhum ator detenha um controle total sobre o processo de realizaçăo dos objetivos, como também raramente é possivel definir/delimitar com precisăo o tipo e o nivel de controle que este dispōe, pode-se afirmar que para cada decisão relativa aos recursos alocados/utilizados existe pelo menos algum ator com algum espaço de controle e consequentemente, com certo nivel de responsabilizaçăo acerca dos resultados.

Outro conceito que alicerça o processo de construção do orçamento é a negociação ou melhor, a decisăo negociada entendida como "a capacidade de integrar e coordenar múltiplas profissionalidades, de guiar comportamentos, de racionalizar as modalidades de funcionamento da organizaçăo" (Rappini, Zavattaro, 1994). Nesse modelo de tomada de decisão, atribui-se aos responsáveis de cada unidade óperativa, autonomia de decisăo quanto à definiçăo das açőes prioritárias, à modalidade de utilizaçăo dos recursos necessários ao conseguimento dos objetivos previamente identificados e negociados. Desse modo, as propostas de orçamento elaboradas em cada CdR processam-se a partir da base do sistema organizacional e văo sendo discutidas, negociadas e sucessivamente integradas entre os demais niveis da estrutura até compor o orçamento global da organização.

A decisão negociada prevê um elevado grau de participação dos diversos atores(nos diversos niveis organizacionais) favorecendo a descentralizaçăo do poder, das responsabilidades e das açס̋es e ainda, promovendo a integraçăo entre as esferas de planejamento, programaçăo e controle.

Esses conceitos articulados possibilitam que o orçamento seja um processo que permite aos responsáveis das unidades:

- Formular objetivamente, em termos sintéticos e verificáveis, os niveis de atividade a serem desenvolvidos, definindo a quantidade físico-técnica e monetária compativeis às finalidades da organização sob o perfil econômico-financeiro;

- Assumir responsabilidades sobre os niveis de resultados alcançados ou que se pretende alcançar;

- Selecionar e combinar modalidades de desenvolvimento das ações que flexibilizem e otimizem a utilizaçăo dos recursos;

- Integrar e coordenar os comportamentos das diversas figuras profissionais no processo de produçăo de serviços. 


\section{A PARTICIPAÇÃO DA ENFERMAGEM NO PROCESSO DE GESTÃO ECONÓMICA NOS SERVIÇOS DE SAÜDE}

No campo da enfermagem os aspectos econômico-financeiros relativos à assistência de enfermagem foram historicamente ignorados. Desde o momento de sua institucionalizaçăo, dentro das estruturas de saúde, a profissăo vem incorporando(principalmente na figura do enfermeiro), como conteúdo de seu trabalho, um conjunto de açōes que envolvem o planejamento, a coordenaçăo, a supervisăo e o controle do trabalho, ou seja, açőes caracteristicas do processo de gerenciamento. Apesar da centralidade das açōes médicas (diagnóstico e terapêutica) que direcionam a dinâmica do processo de trabalho em saúde, são os enfermeiros que efetivamente gerenciam as unidades assistenciais, viabilizando, favorecendo e criando condições técnicas e politicas para que o trabalho cotidiano aconteça.

Entre as açőes de natureza gerencial, o controle talvez seja a mais empregada pelos enfermeiros para garantir o andamento do trabalho na instituiçăo. Entretanto, ao concretizarem essa açăo em sua prática diária, esta assume um significado muito próximo à idéia de fiscalização traduzida na verificaçăo permanente e contínua da execução correta dos procedimentos, no cumprimento rigoroso das regras, normas e rotinas da organização tentando com isso garantir comportamentos padronizados das pessoas que nela atuam e respondendo às exigências formais estabelecidas em conformidade ao modelo burocrático predominante nos serviços de saúde, em especial, nos hospitais Tais caracteristicas do controle têm limitado a motivação dos trabalhadores envolvidos na produção da assistência de enfermagem; cerceado qualquer possibilidade de participação e de inovaçăo na organização do trabalho; e ainda, gerado inúmeros conflitos com os demais profissionais de saúde. Em sintese, as açŏes de controle permanecem centradas nas pessoas e não nos resultados do trabalho, que seriam garantir respostas quali-quantitativas satisfatórias aos problemas de saúde da clientela atendida.

Pensar a elaboração de um orçamento específico para a área de enfermagem articulado ao orçamento das demais áreas da instituição permite a redefinição de níveis de responsabilidade organizacional e econômica vinculados a graus de controlabilidade sobre os fatores produtivos, os quais poderão reconfigurar novos espaços de autonomia, ainda que relativos, na gestão dos recursos alocados na produçăo e, desse modo, tornar objetiva e visivel a sua contribuiçăo econômico financeira nos serviços de saúde.

Um orçamento de enfermagem exprimirá, em termos quantitativos e qualitativos, as atividades desenvolvidas sob o perfil monetário e físico-técnico; representará um conjunto de "intençōes", de objetivos a serem alcançados em um determinado periodo de tempo explicitando a relaçăo entre o volume de atividades realizadas segundo suas caracteristicas especificas $\mathrm{e}$ respectivos custos.

A construçăo de um orçamento próprio implica para a enfermagem:

- A identificaçăo e quantificaçăo das açōes que desenvolve de modo a representar a globalidade e complexidade da assistência em base às concretas exigências/necessidades dos pacientes atendidos, o que significa caracterizar o produto de seu trabalho;

- A definiçăo, mensuração e avaliaçăo da quantidade de recursos empregados(ou a empregar) na realização dessas ações, em termos de trabalho de seus agentes (hora/homem trabalho) e de outros fatores produtivos(materiais, equipamentos, processos de formaçăo etc..)(Anselmi, 1996-1997).

Assumir responsabilidades de caráter econômico-financeiro num serviço de saúde, tomando $o$ orçamento como instrumento para tal, requer a incorporaçăo de um conjunto de conhecimentos, habilidades e competências que instrumentalizarão a profissăo para o desenvolvimento de um processo de gestăo inovador, mais autônomo e orientado à melhoria da eficiência, eficácia e economicidade. 
Nesse momento, a preocupaçăo com as ineficiências do sistema e o crescimento continuo dos gastos em saúde têm favorecido e estimulado o debate acerca das mudanças e da questão da racionalização entendida "como uma pauta de intervençőes dirigidas ao incremento da eficiência gerencial do sistema" (Mendes, 1996)a qual embora represente soluçăo parcial à crise da saúde é imprescindivel para dar maior efetividade ao sistema. Entretanto, ao nosso ver, alguns aspectos criticos se fazem presentes quando se pensa a introduçăo de processos de controle econômico no âmbito da gestão dos serviços de saúde no Brasil, tais como:

- ausência, especialmente no setor público, de uma cultura institucional voltada aos aspectos econômicos no processo de gestão dos serviços bem como de uma "vontade" politica que redirecione o funcionamento dos serviços em base a uma maior eficiência, em decorrência dos múltiplos conflitos de interesse que isto comporta, principalmente, quando se pensa que ao setor público compete exercer o papel de regulador do sistema;

- uma forte burocratização do sistema onde prevalece ainda o controle sobre a forma como são realizadas as operaçōes e os atos; a ênfase em procedimentos administrativos extremamente "rigidos" implicando em um baixo grau de motivação dos diversos profissionais envolvidos nos processos de prestação de serviços;

- a adoçăo, dentro dos hospitais, de um sistema de contabilidade de custos e orçamentário altamente centralizado, ou seja, que vem definido e operacionalizado nos niveis hierárquicos superiores da organização com o suporte do setor de contabilidade. Desse modo, os responsáveis das diversas unidades dispõem de pouco espaço para assumirem responsabilidades na formulaçăo dos objetivos/resultados a alcançar, sobre os recursos que são utilizados(ou a utilizar) bem como um baixo grau de autonomia sobre a efetiva gestão da unidade em base a critérios de eficiência, eficácia e economicidade;

- um sistema informativo precário, pouco fidedigno, onde as metodologias adotadas năo possibilitam comparar informações, e ainda, escassez de indicadores (econômicos e não) que suportem os processos decisórios organizacionais (Anselmi, 1996-1997).

$\mathrm{Na}$ área da enfermagem, além dos aspectos mencionados anteriormente, a adoção da perspectiva econômica da gestão, depara-se com algumas limitaçōes, entre elas:

- uma forte centralização em seus processos decisórios, sejam estes técnicos como organizacionais, limitando as possibilidades de participaçăo e envolvimento de seus diversos agentes;

- processos de formação profissional voltados principalmente aos aspectos assistenciais da profissão(que săo fundamentais) em detrimento de conteúdos e instrumentos de caráter gerencial(programação, avaliação e controle das atividades/programas), dificultando uma atuação mais efetiva sob o perfil da eficiência, eficácia e economicidade.

Entretanto, algumas possibilidades podem ser delineadas com vistas à superaçăo desses aspectos. Talvez o momento inicial seria o desencadeamento de um processo de sensibilização cultural ao nivel organizacional envolvendo todos os seus atores e em especial os dirigentes, que contemplasse:

- a valorizaçăo dos aspectos econômicos da gestão, na qual o modelo de controle a ser adotado estivesse centrado nos resultados obtidos (ou a obter) em termos de eficiência e eficácia, de modo a superar o modelo burocrático ainda fortemente presente no âmbito dos serviços públicos de saúde;

- a funcionalidade do serviço considerando a complexidade resultante da multiplicidade e diversidade dos recursos utilizados, o que favoreceria a inovação, a criatividade e a experimentação de modelos organizacionais mais participativos. A adoção de mecanismos de descentralização das decisões e concomitante responsabilização sobre o uso efetivo dos recursos poderia contribuir para ampliar niveis de resolutividade dos problemas de saúde apresentados pela clientela atendida na organização;

- o desenvolvimento de atitudes, conhecimentos e competências relativas aos conceitos 
da abordagem econômico-gerencial, buscando integrar os aspectos/conteúdos da profissão aos aspectos/conteúdos da gestão econômica;

- a adoçăo de metodologias que possibilitassem a identificaçăo/caracterização das exigências assistenciais dos pacientes em termos de horas de trabalho requeridas para atender suas necessidades, de modo a qualificar o trabalho e melhorar a produtividade (Anselmi, 19961997).

\title{
CONSIDERAÇÕES FINAIS
}

Os limites e possibilidades apontadas neste trabalho com vistas à introdução do processo de controle econômico e respectivos instrumentos sinalizam alguns caminhos para a construção de uma atuação mais explicita e consolidada da enfermagem no processo de formulação do orçamento organizacional. A participação nesse processo deverá contemplar a transparência nos processos decisórios bem como a responsabilização sobre a definiçăo dos objetivos e a avaliaçăo dos resultados assistenciais e econômico-financeiros, articulados em momentos de negociaçăo entre os diversos atores organizacionais de modo a redimensionar e reconfigurar novas modalidades de gestăo para os serviços de enfermagem.

\begin{abstract}
The study presents some reflections on the possibilities and limitations of the rationalization and flexibilization of the management process of the health services under the economic perspective, focussing on the introduction of mechanisms and instruments centred in the economic and organizational responsabilization of the resources and nursing participation in these processes. Authors discuss the adoption of a system of economic control in order to coordinate the interests of the several subjects involved; to privilege the results of the processes and to improve the economic combination of the resouces. Under this perspective, two concepts are considered relevant in the elaboration of the budget of the Nursing Services: the controllability of the resouces and the negotiation in the processes of allocation and utilization of these resources. The use of these concepts in the organization of health services, especifically in nursing area, creates new possiblities of participation in the processes of services production, enabling more transparency in the decision processes and restructuring new modalities of management for the nursing services.
\end{abstract}

KEYWORDS: process of economic management, economic control, budget of the Nursing Services.

RESUMEN: Este articulo presenta algunas reflexiones sobre las posibilidades y limites de la racionalización y flexibilización del proceso de gestión en los servicios de salud bajo la perspectiva económica y enfoca la introducción de mecanismos e instrumentos centralizados en la responsabilización económica y organizacional de los recursos y la participación de la enfermeria en estos procesos. Se discute la adopción de un sistema de control económico que pueda coordinar los intereses de los diversos sujetos arrollados; privilegie los resultados de los procesos y mejore la combinación económica de los recursos. Con esa perspectiva dos conceptos son considerados relevantes en la elaboración del presupuesto del Servicio de Enfermeria: la fiscalización de los recursos y la negociación en los procesos de consignación, destinación y utilización de ellos. La operacionalización de esos conceptos en el ámbito de la (re)organización de los servicios de salud. más especificamente, en el área de enfermeria, crea nuevas posibilidades de participación en los 
procesos de producción de servicios y asegura mayor transparencia en los procesos decisivos y reconfigurando nuevas modalidades de gestión para los servicios de enfermeria.

PALABRAS CLAVE: proceso de gestión económica, control económico, presupuesto del Servicio de Enfermeria.

\section{REFERÊNCIAS BIBLIOGRÁFICAS}

ANESSI,E. II governo della sanità nei paesi industrializzati: modelli a confronto. Management \& Economia Sanitaria. Roma, n.3,p.19-41, luglio-settembre, 1993.

ANSELMI, M. L. II quadro di niferimento per la formulazione del budget del personale infermieristico nelle aziende sanitarie. Milano, 1996-1997. Tesi(Diploma in Health Services Management. III Edizione). University of Birmingham - Scuola di Direzione Aziendale, Università Luigi Bocconi.

ANTHONY, R. N; YOUNG,D.W. Controllo di gestione per il settore non profit. Milano: McGraw-Hill, 1992.

BORGONOVI, E. Controllo economico e caratteristiche del sistema di produzione-erogazione dei servizi. In: BORGONOVI, E. (a cura di) /l controllo economico nelle aziende sanitarie. Milano: Egea, 1990.

BORGONOVI, E. Principi e sistemi aziendali per le amministrazioni pubbliche. Milano:Egea, 1996.

MEDICI, A. C. Economia e financiamento do setor saúde no Brasil. Faculdade de Saủde Pública, Universidade de São Paulo, 1994.

MENDES, E. V. Uma agenda para a saúde. São Paulo: Hucitec, 1996.

PESSINA, E. A.; BERGAMASCHI,M.; ZAVATTARO,F. L'introduzione di sistemi gestionali nelle aziende sanitarie: l'esperienza delle Regione Emilia-Romagna. Seconda fase: il budget a base zero. Management \& Economia Sanitaria. Roma, n.10, p.60-71, aprile-giugno, 1994.

RAPPINI, V. \& ZAVATTARO, F. Manuale operativo per l'introduzione del sistema budget nelle aziende sanitarie della Regione Lombardia. Milano, Divisione Amministrazioni Publiche. Università Luigi Bocconi,1994. v.1-2. 